\title{
A p-(Al,Ga)As/GaAs MODULATION-DOPED HETEROSTRUCTURE PREPARED BY LIQUID PHASE EPITAXY
}

\author{
SI-CHEN LEE and TSAN-BIN SUN \\ Department of Electrical Engineering, National Taiwan University, Taipei, Taiwan, China
}

(Received 6 February 1986; accepted in revised form 15 April 1986)

\begin{abstract}
A p-type (Al,Ga)As/GaAs modulation-doped heterostructure was successfully fabricated by liquid phase epitaxy. Its mobility and sheet hole concentration as a function of the aluminum composition were studied in the temperature range of $77-400 \mathrm{~K}$. It is found that the hole mobility is enhanced whenever the aluminum mole fraction $x$ is between $x=0.05$ and 0.5 . The maximum mobility obtained at $77 \mathrm{~K}$ is $3200 \mathrm{~cm}^{2} / \mathrm{V} \mathrm{sec}$ for $\mathrm{Al}_{0.2} \mathrm{Ga}_{0.8} \mathrm{As} / \mathrm{GaAs}$ with a $300 \AA$ spacer layer. It is concluded that the hole mobility can be enhanced at low temperature as long as the holes are spatially separated from their parent atoms no matter whether due to a valence band discontinuity or an impurity concentration gradient.
\end{abstract}

Keywords: Modulation-doped, heterostructure, liquid phase epitaxy, AlGaAs, mobility.

\section{INTRODUCTION}

The p-type modulation-doped (MD) heterostructure has attracted much attention [1-3] recently for two reasons: first, it has practical application in $\mathrm{GaAs}$ integrated circuits such as complementary logic devices [4], and second, it provides a chance to study the valence band discontinuity at the AlGaAs/GaAs heterojunction interface $[2,3]$. In the past, one tended to relate the mobility enhancement phenomenon to the formation of a two-dimensional (2D) hole gas (2 DHG) [5]. In this paper, however, we will show that the hole mobility can be enhanced even in a MD structure with a negligible valence band discontinuity. Liquid phase epitaxy (LPE) was applied to see whether this technique is feasible for growing ultra-thin layer structures. In addition, the aluminum composition $x$ is varied from $0.5-0.05$ to see whether a high valence band discontinuity is necessary to realize the mobility enhancement phenomenon.

\section{EXPERIMENTS}

The MD heterostructure used in this study was grown on a $\mathrm{Cr}$-doped $\mathrm{GaAs}$ substrate consisting of a $1-1.5 \mu \mathrm{m}$ thick $\left(\mathrm{p}^{-}\right)$-GaAs buffer layer, a thin undoped $(\mathrm{Al}, \mathrm{Ga})$ As spacer layer and a $\left(\mathrm{P}^{+}\right)-(\mathrm{Al}, \mathrm{Ga}) \mathrm{As}$ top layer. In order to grow this heterostructure using LPE, two requirements must be satisfied, i.e. the ability to grow (1) a few hundred $\AA$ thick epilayer, and (2) a high purity GaAs buffer layer. To satisfy the first requirement, the gallium melts had to pass over two dummy wafers placed in front of the substrate during growth to decrease the degree of supersaturation. In addition, the melt thickness was kept very thin $(<2.5 \mathrm{~mm})$ and a polycrystal GaAs was placed on top of each melt. To further reduce the layer thickness, a lower growth temperature at $700^{\circ} \mathrm{C}$ was tried. The $\mathrm{Al}_{0.5} \mathrm{Ga}_{0.5}$ As layer thus obtained was less than $100 \AA$ thick. Unfortunately, the background impurity, which is n-type at a concentration about $10^{16} \mathrm{~cm}^{-3}$, is too high to meet the second requirement. Thus, the growth temperature was set at $800^{\circ} \mathrm{C}$ in this study in order to reduce the background impurity concentration to about $10^{15} \mathrm{~cm}^{-3}$.

Figure 1 displays the thickness $d$ of the $\mathrm{Al}_{0.5} \mathrm{Ga}_{0.5}$ As layer as a function of the growth time $t$. The cooling rate is the independent parameter. The thickness was determined using an $\alpha$-step by first selectively etching part of the epilayer in a $1 \mathrm{HF}: 1 \mathrm{H}_{2} \mathrm{O}$ solution. Since the heterojunction is typically graded during LPE growth, the measured epilayer thickness is probably $100 \AA$ thinner than the real value. It is clear from the figure that for $t>10 \mathrm{sec}$,

$$
d=A t^{0.68}
$$

where $A$ is a constant which is equal to 47 or $76 \AA \mathrm{sec}^{-1}$ depending on whether the cooling rate is 0.1 or $0.2^{\circ} \mathrm{C} \mathrm{min}^{-1}$. The initial growth thickness is about $200 \AA$, which is caused by dynamical inequilibrium during the movement of the melt [6]. This sets a lower limit to the layer thickness that can be grown in our LPE system at a growth temperature of $800^{\circ} \mathrm{C}$. When the Al composition $x$ decreases to below 0.45 , the growth rate tends to increase and its thickness is estimated from the growth time using our existing steady-state growth rate data. Usually the growth time is $3 \mathrm{sec}$ (pushover) for the undoped AlGaAs spacer layer unless otherwise specified, and one min for the top $\left(\mathrm{P}^{+}\right) \mathrm{AlGaAs}$ layer. The cooling rate is kept at $0.1{ }^{\circ} \mathrm{C} \mathrm{min}^{-1}$. The GaAs buffer layer is typically $1-1.5 \mu \mathrm{m}$ thick and doped with 0.0015 at. $\% \mathrm{Ge}$ 


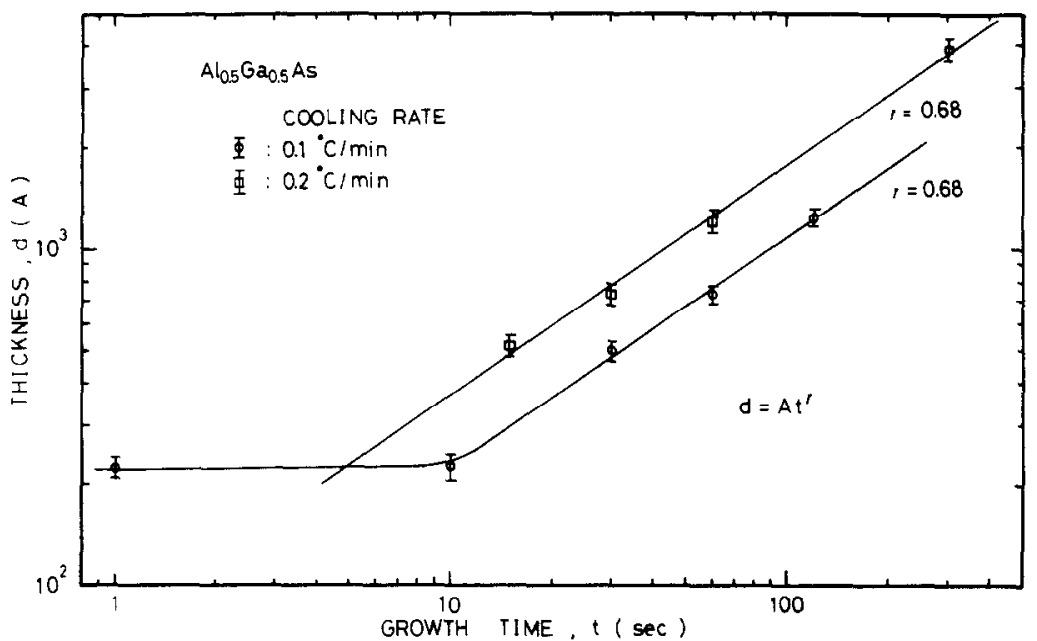

Fig. 1. The $\mathrm{Al}_{0.5} \mathrm{Ga}_{0.5}$ As epilayer thickness as a function of the growth time. The cooling rate is the independent parameter.

to compensate the background donor. The resultant net acceptor density $\left(N_{A}-N_{D}\right)$ turns out to be $10^{15} \mathrm{~cm}^{-3}$.

After the structure is grown, a photolithography procedure is used to define the contact region. $\mathrm{Au}-\mathrm{Zn}$ is vacuum evaporated on to the sample and lifted off. The sample is then annealed at $450^{\circ} \mathrm{C}$ for $3.5 \mathrm{~min}$ to form an ohmic contact. Afterwards, a second photolithography operation is performed and followed by a mesa etch in a $1 \mathrm{H}_{2} \mathrm{SO}_{4}: 8 \mathrm{H}_{2} \mathrm{O}_{2}: 1 \mathrm{H}_{2} \mathrm{O}$ solution to define the van der Pauw bridge pattern. During the van der Pauw measurement, the magnetic field was set at $3 \mathrm{KG}$ and the temperature was varied from $77-400 \mathrm{~K}$. One of the samples, No. 447 , was measured down to $4 \mathrm{~K}$.

\section{RESULTS AND DISCUSSIONS}

During the van der Pauw measurement, the current flowing between the top metal contacts consists of three components, i.e. (1) $I_{1}$ which flows through the top $\left(\mathrm{P}^{+}\right)$AlGaAs layer, (2) $I_{S}$ through the AlGaAs/GaAs interface, and (3) $I_{2}$ through the $(\mathrm{p}-) \mathrm{GaAs}$ buffer layer. Therefore, in order to determine which component dominates, the following procedures must be followed: first, the Ge-doped single AlGaAs layers were studied thoroughly, the electrical properties of the MD heterostructure were measured and, finally, the AlGaAs layer was removed to see whether the conducting current $I_{2}$ is significant.

\subsection{Characteristics of $(\mathrm{Al}, \mathrm{Ga}) \mathrm{As}$ doped with $1 \% \mathrm{Ge}$}

Figure 2 shows the hole concentration of the $1 \%$ Ge-Doped (Al,Ga)As layers as a function of the reciprocal temperature. The aluminum mole fraction $x$ is the independent parameter. The thickness of each layer is larger than $5 \mu \mathrm{m}$. By using the charge neutrality condition [7] and an assumption of high compensation to fit these curves, the zero degree acceptor ionization energies as a function of $x$ can be extracted. The data are shown in Fig. 3. Our data at low $x$ are much smaller than those of Ref. [8], partly because the ionization energies in Ref. [8] were directly extracted from the slope of the curve and thus usually overestimated [8].

The mobilities vs temperature plot on a log-log scale is shown in Fig. 4. Obviously, the mobilities are limited by polar optical phonon scattering at high temperature and by ionized impurity scattering at low temperature. It is also clear that at $T<150 \mathrm{~K}$,

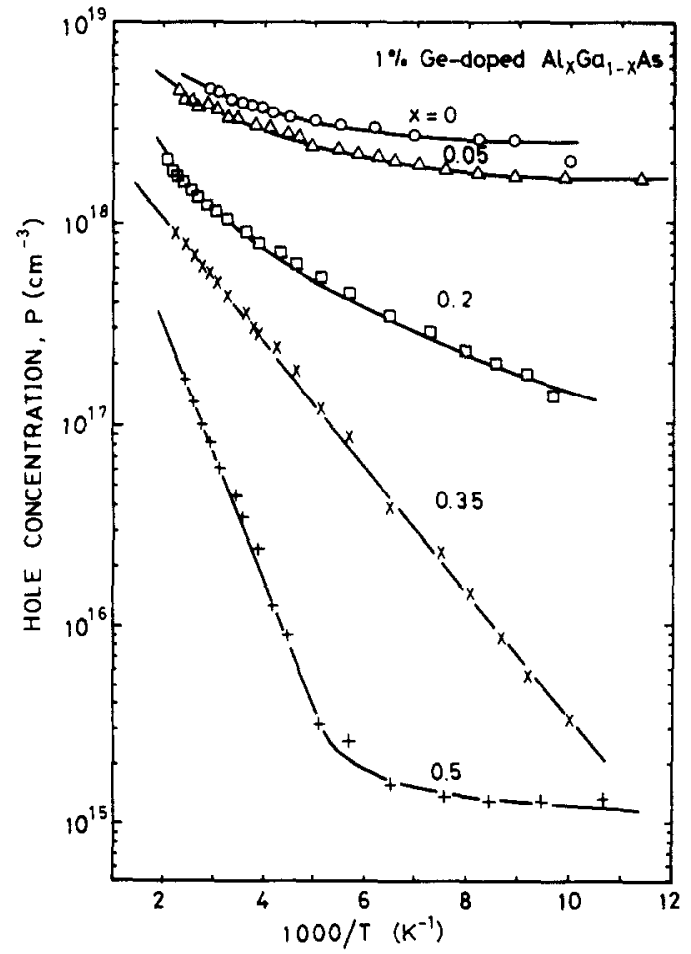

Fig. 2. Hole concentration vs the reciprocal temperature for $1 \% \mathrm{Ge}$-doped $\mathrm{Al}_{r} \mathrm{Ga}_{1-x}$ As layers. 


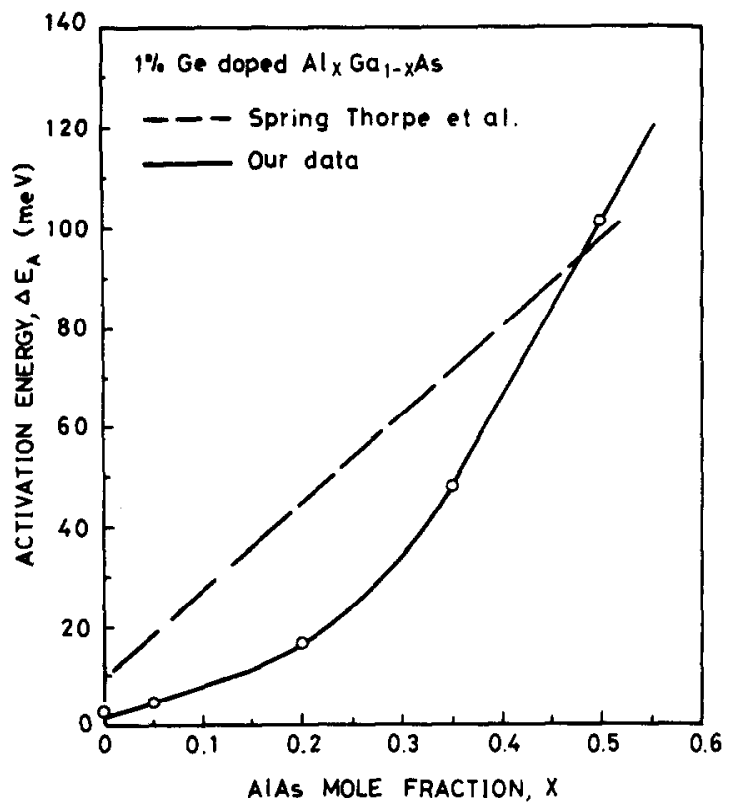

Fig. 3. Geo ionization energy as a function of the AlAs mole fraction. Broken line is quoted from Ref. [8] and the solid line is our data.

the hole mobility is higher for those layers with higher $\mathrm{Al}$ composition due to their smaller ionized impurity concentration (freeze-out effect).

\subsection{Characteristics of $\mathrm{p}-(\mathrm{Al}, \mathrm{Ga}) \mathrm{As} / \mathrm{GaAs} M D$ structure}

Figure 5 displays the sheet hole concentration vs reciprocal temperature for the $\mathrm{Al}_{0.5} \mathrm{Ga}_{0.5} \mathrm{As} / \mathrm{GaAs}$ MD heterostructure with (No. 411) or without (No. 412) a $200 \AA$ spacer layer. The top $\left(\mathrm{P}^{+}\right) \mathrm{Al}_{0.5} \mathrm{Ga}_{0.5} \mathrm{As}$ layer is $750 \AA$ thick. The sheet hole concentration of sample 412 decreases slightly as the temperature is

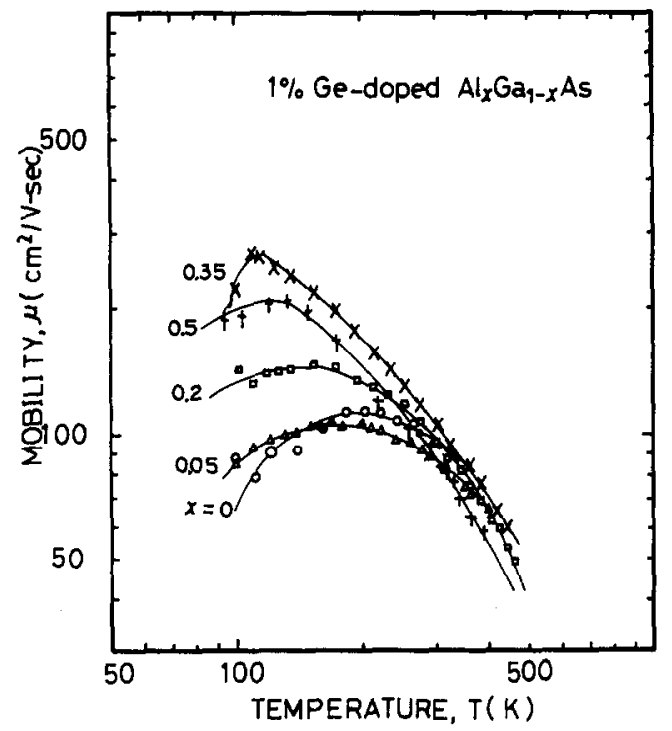

Fig. 4. Hole mobility vs temperature for $1 \%$ Ge-doped $\mathrm{Al}_{x} \mathrm{Ga}_{1-x}$ As.

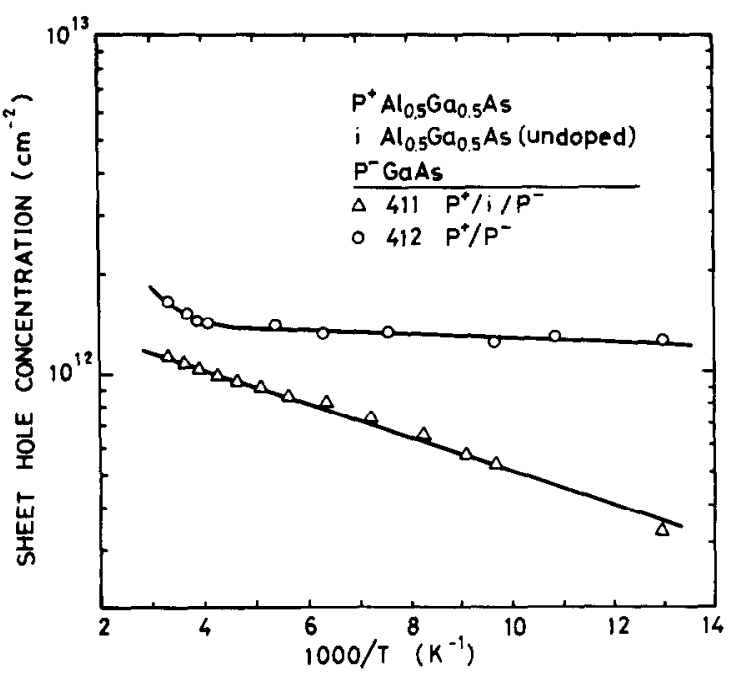

Fig. 5. Sheet hole concentration vs reciprocal temperature for $\mathrm{p}-\mathrm{Al}_{0.5} \mathrm{Ga}_{0.5} \mathrm{As} / \mathrm{GaAs} \mathrm{MD}$ heterostructure.

lowered and quickly approaches a constant value of about $1.2 \times 10^{12} \mathrm{~cm}^{-2}$. These are just the characteristics of a $2 \mathrm{D}$ system $[9,10]$. The hole concentration of sample 411 is less than that of sample of 412 and shows a slight activation energy of about $9 \mathrm{meV}$ that is due to the insertion of the spacer layer.

Other evidence for the existence of $2 \mathrm{DHG}$ is the observation of the mobility enhancement phenomenon, as shown in Fig. 6. The mobility of sample 412 increases from $150 \mathrm{~cm}^{2} / \mathrm{V} \mathrm{sec}$ at room temperature to about $400 \mathrm{~cm}^{2} / \mathrm{V} \mathrm{sec}$ at $77 \mathrm{~K}$, which is larger than that of the $1 \% \mathrm{Ge}$-doped single $\mathrm{Al}_{0.5} \mathrm{Ga}_{0.5} \mathrm{As}$ epi-

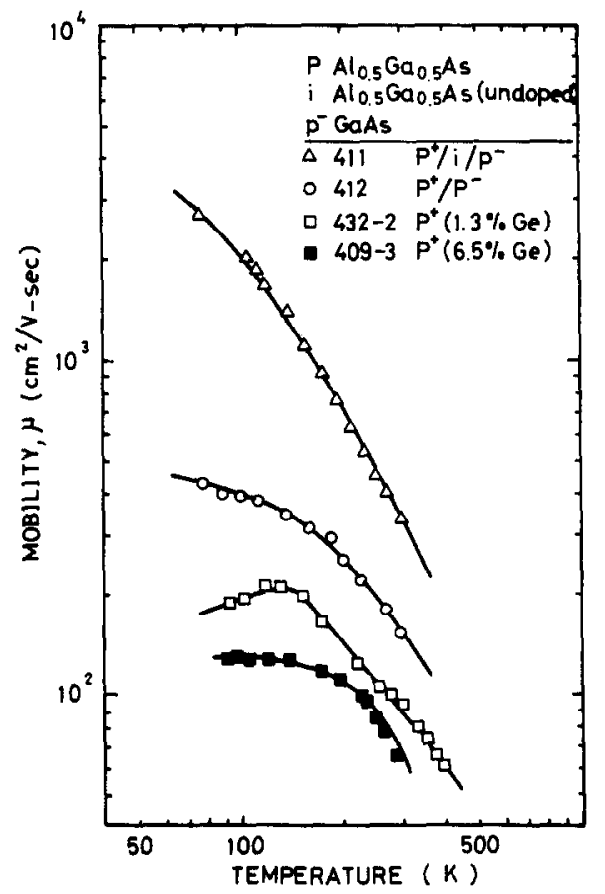

Fig. 6. Hole mobility vs temperature for $\mathrm{p}-\mathrm{Al}_{0.5} \mathrm{Ga}_{0.5} \mathrm{As} /$ GaAs MD heterostructure. 


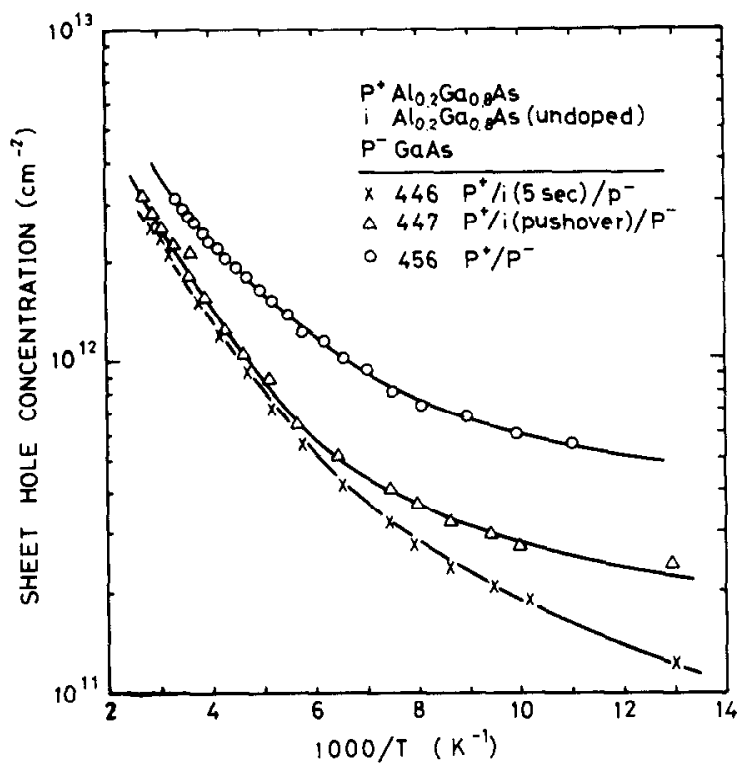

Fig. 7. Sheet hole concentration vs reciprocal temperature for $\mathrm{p}-\mathrm{Al}_{0.2} \mathrm{Ga}_{0.8} \mathrm{As} / \mathrm{GaAs} \mathrm{MD}$ heterostructure.

layer. The mobility of sample 411 is enhanced even higher, increasing from 350 at $300 \mathrm{~K}$ to $2800 \mathrm{~cm}^{2} / \mathrm{V} \mathrm{sec}$ at $77 \mathrm{~K}$. This mobility enhancement phenomenon is certainly not due to the top $\left(\mathrm{P}^{+}\right)$AlGaAs layer. It is also not due to the GaAs buffer layer, since after the top $\mathrm{Al}_{0.5} \mathrm{Ga}_{0.5} \mathrm{As}$ layer is removed by chemical etching, the remaining GaAs buffer layer appears to be highly resistive, i.e. four orders of magnitude higher resistance. This can only be explained by assuming that the GaAs layer is completely pinched-off by the top surface and bottom epilayer-substrate depletion regions, which indicates that the net acceptor concentration in the $\left(\mathrm{p}^{-}\right.$) GaAs layer is low, i.e. $\$ 10^{15} \mathrm{~cm}^{-3}$.

As the aluminum mole fraction decreases to 0.2 , the valence band discontinuity while using the 65-35 rule $[2,11,12]$ is only $0.09 \mathrm{eV}$ which makes it difficult to confine the transferred holes within the potential notch. Figure 7 displays the sheet hole concentration as a function of the reciprocal temperature for sample 456 without a spacer layer, and samples 446 and 447 with a $350 \AA$ thick spacer layers. The $\left(\mathrm{P}^{+}\right) \mathrm{Al}_{0.2} \mathrm{Ga}_{\text {0.8 }}$ As layer is $1500 \AA$ thick. As the temperature is lowered, the sheet hole concentration exhibits a strong freeze-out effect with a tendency to slow down at low temperature. When the temperature of sample 447 is lowered to below $20 \mathrm{~K}$, it becomes highly resistive, which indicates that the 2 DHG does not exist in sample 447.

The mobility data is shown in Fig. 8, the mobility of sample 447 at $300 \mathrm{~K}$ being about $150 \mathrm{~cm}^{2} / \mathrm{V} \mathrm{sec}$, about the same as that of the $1 \%$ Ge-doped $\mathrm{Al}_{0.2} \mathrm{Ga}_{0.8} \mathrm{As}$ single layer, and is enhanced to $3200 \mathrm{~cm}^{2} / \mathrm{V} \mathrm{sec}$ at $77 \mathrm{~K}$. The mobility of sample 456 is 150 at $300 \mathrm{~K}$ and $660 \mathrm{~cm}^{2} / \mathrm{V} \mathrm{sec}$ at $77 \mathrm{~K}$. It is clear that the mobility enhancement phenomenon of sample 447 is not due to the formation of $2 \mathrm{DHG}$ but

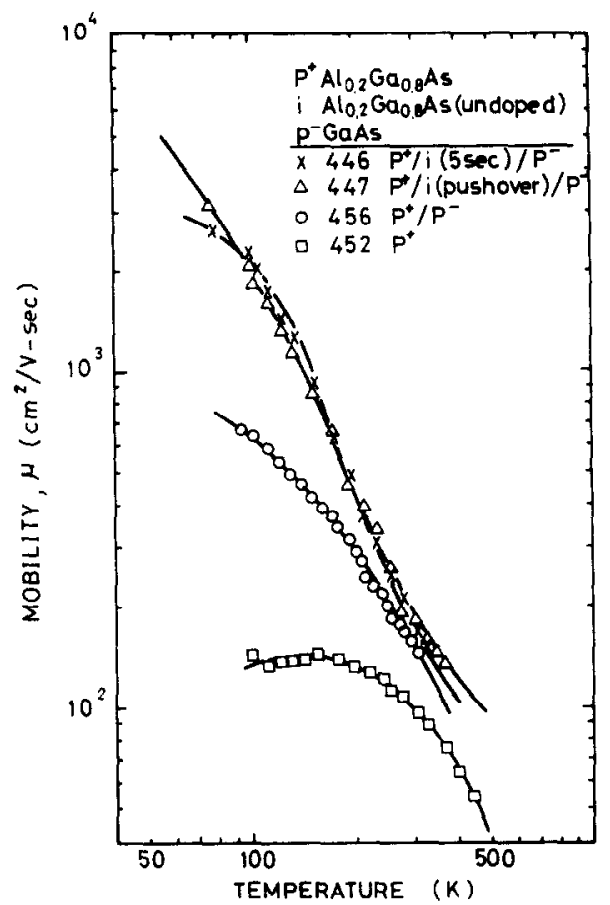

Fig. 8. Hole mobility vs temperature for $p-\mathrm{Al}_{0.2} \mathrm{Ga}_{0.8} \mathrm{As} /$ $\mathrm{GaAs}$ MD heterostructure.

simply the results of hole transfer from the $\left(\mathrm{p}^{+}\right) \mathrm{Al}_{0.2} \mathrm{Ga}_{0.8}$ As layer to the ( $\left.\mathrm{p}^{-}\right) \mathrm{GaAs}$ side caused by the impurity concentration gradient. The separation of holes from their parent acceptors accounts for the mobility enhancement.

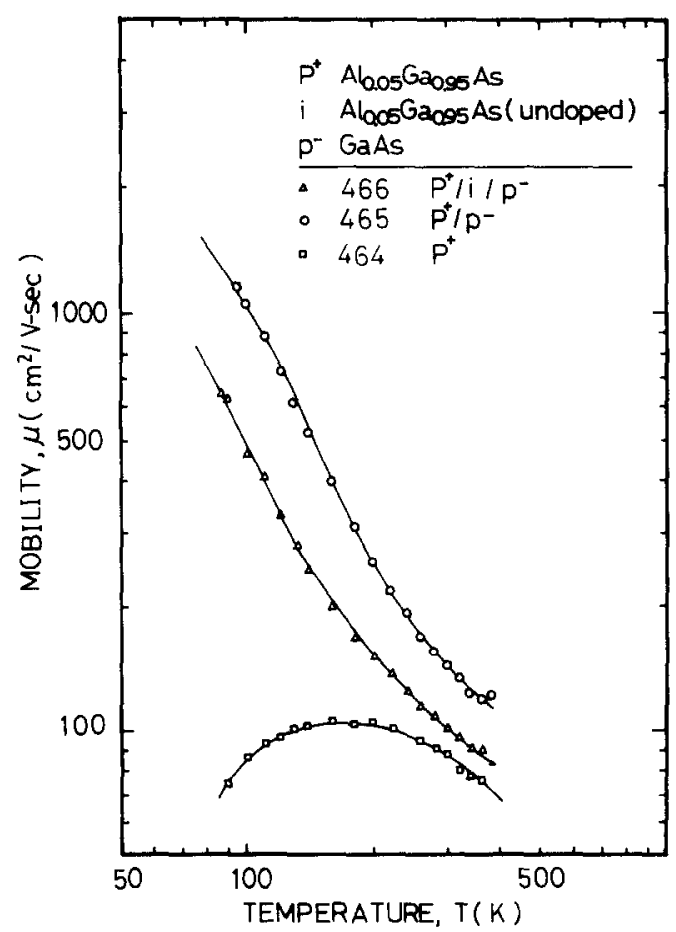

Fig. 9. Hole mobility vs temperature for $\mathrm{p}-\mathrm{Al}_{0.05} \mathrm{Ga}_{0.95} \mathrm{As} /$ GaAs MD heterostructure 


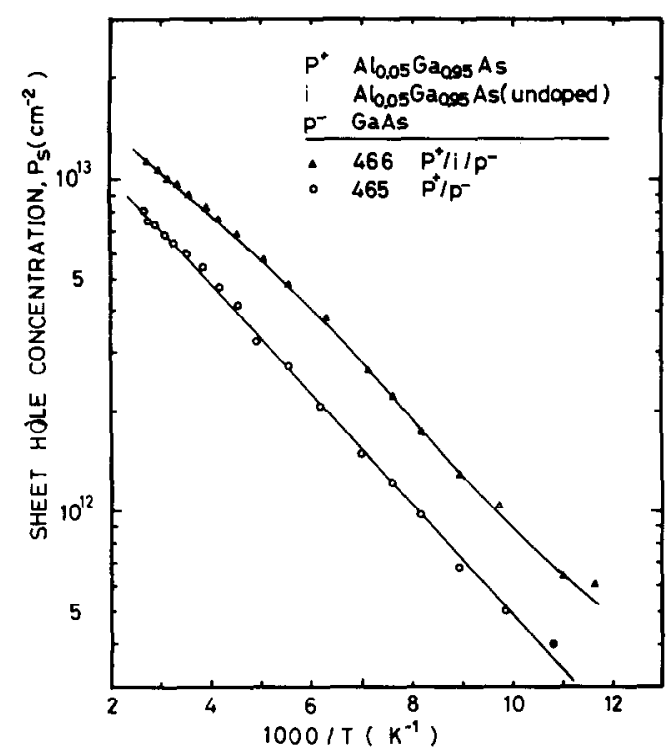

Fig. 10. Sheet hole concentration vs reciprocal temperature for $\mathrm{p}-\mathrm{Al}_{0.05} \mathrm{Ga}_{0.95} \mathrm{As} / \mathrm{GaAs} \mathrm{MD}$ heterostructure.

To explore this further, the aluminum mole fraction was reduced to 0.05 . Now the valence band discontinuity is only $22 \mathrm{meV}$ and is no longer important in determining the charge transfer. It is clear that again the hole mobility is enhanced, as shown in Fig. 9, simply due to the separation of holes from their parent acceptors. The mobility of sample 465 without a spacer layer is 140 at $300 \mathrm{~K}$, but enhanced to $1300 \mathrm{~cm}^{2} / \mathrm{V} \mathrm{sec}$ at $90 \mathrm{~K}$, while sample 466 with a $400 \AA$ spacer layer is only enhanced to $620 \mathrm{~cm}^{2} / \mathrm{V} \mathrm{sec}$ at $90 \mathrm{~K}$. This is contrary to the results obtained above. The reason is probably due to the fact that the transferred hole concentration within the spacer layer is now larger than that in the $\left(\mathrm{p}^{-}\right) \mathrm{GaAs}$ buffer layer. The residual impurities in this layer and the two rough interfaces that the transferred holes see may reduce the mobility more seriously than that of sample 465 without a spacer layer.

The most significant fact is that the measured hole concentration $p_{s}$, as shown in Fig. 10, does not originate from either the top $\left(\mathrm{P}^{+}\right) \mathrm{Al}_{0.05} \mathrm{Ga}_{0.95}$ As layer or the bottom ( $\left.\mathrm{p}^{-}\right) \mathrm{GaAs}$ buffer layer, but from the transferred holes. The reason is that the hole concentration over the entire measured range is beyond $5 \times 10^{11} \mathrm{~cm}^{-2}$, which is too high to be attributed to the conducting channel in the $\left(\mathrm{p}^{-}\right) \mathrm{GaAs}$ buffer layer. An extremely important conclusion can then be drawn from this fact; namely that there is no need to form a $2 \mathrm{D}$ electron or hole gas to observe the mobility enhancement phenomenon, since only the separation of carriers with their parent impurities is essential. The reason that the hole concentration of sample 466 with a spacer layer is higher than that of sample 465 without a spacer layer is unknown at present.

The samples were illuminated at low temperature and no persistent photoconductivity effect was observed, which indicates that there exist no DX centres [13] in our p-type MD structure.

\section{CONCLUSIONS}

A p-type MD heterostructure has been successfully fabricated by the LPE technique. The thinnest $\mathrm{Al}_{x} \mathrm{Ga}_{1-x} \mathrm{As}$ epilayer that can be grown in our LPE system at $800^{\circ} \mathrm{C}$ is $200 \AA$ for $x=0.5$. A mobility enhancement phenomenon was indeed observed whatever the aluminum composition. It can be concluded that the mobility of the transferred holes could be enhanced as long as they are separated from their parent atoms, whether due to the valence band discontinuity or due to the impurity density gradient.

\section{RFFERENCES}

1. Stormer H. L., Gossard A. C., Wiegmann W., Blondel R. and Baldwin K., Appl. Phys. Lett. 44, 139 (1984).

2. Wang W. 1., Mendez E. E. and Stern F., Appl. Phys. Lett. 45, 639 (1984).

3. Kiehl R. A. and Gossard A. C., IEEE Electron Device Lett. 5, 420 (1984).

4. Tiwari S. and Wang W. I., IEEE Electron Device Lett. 5, 333 (1984).

5. Kiehl R. A. and Gossard, IEEE Electron Device Lett. 5, 521 (1984)

6. Tamargo M. C., Reynolds C. L., Jr. and Kunkel R. I., J. Cryst. Growth 71, 421 (1985).

7. Stillman E. and Wolfe C. M., Thin Solid Films 31, 69 (1976).

8. Spring-Thorpe A. J., King F. D. and Becke A., J. Electron Mater. 4, 101 (1975).

9. Collins D. M., Mars D. E., Fisher B. and Kocot C., J. Appl. Phys. 54, 857 (1983).

10. Kunzel H., Fisher A., Knecht J. and Ploog K., Appl. Phys. A32, 69 (1983).

11. Kroemer H., Chien W. Y., Harris J. S., Jr and Edwall D. D., Appl. Phys. Lett. 36, 295 (1980).

12. Arnold D. A., Ketterson A., Henderson T., Klem J. and Morkoc H., Appl. Phys. Lett. 45, 1237 (1984).

13. Lang D. V. and Logan R. A., Phys. Rev. B19, 1015 (1979). 